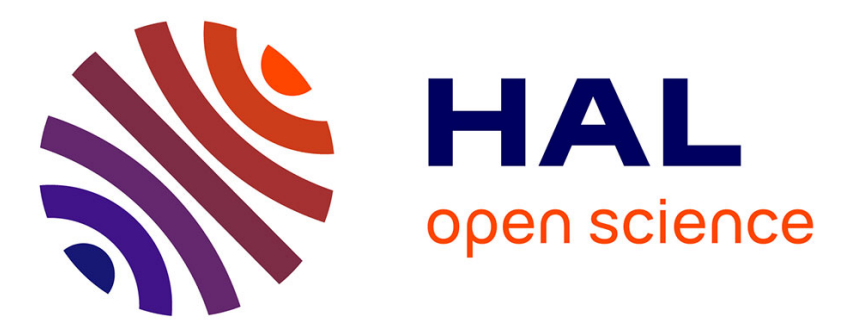

\title{
Comparison between 2D and 3D applications of the coupled criterion to crack initiation prediction of scarf adhesive joints
}

\author{
Aurélien Doitrand, Dominique Leguillon
}

\section{- To cite this version:}

Aurélien Doitrand, Dominique Leguillon. Comparison between 2D and 3D applications of the coupled criterion to crack initiation prediction of scarf adhesive joints. International Journal of Adhesion and Adhesives, 2018, 85, pp.69-76. 10.1016/j.ijadhadh.2018.05.022 . hal-01905668

\section{HAL Id: hal-01905668 \\ https://hal.sorbonne-universite.fr/hal-01905668}

Submitted on 26 Oct 2018

HAL is a multi-disciplinary open access archive for the deposit and dissemination of scientific research documents, whether they are published or not. The documents may come from teaching and research institutions in France or abroad, or from public or private research centers.
L'archive ouverte pluridisciplinaire HAL, est destinée au dépôt et à la diffusion de documents scientifiques de niveau recherche, publiés ou non, émanant des établissements d'enseignement et de recherche français ou étrangers, des laboratoires publics ou privés. 


\title{
Comparison between 2D and 3D applications of the coupled criterion to crack initiation prediction of scarf adhesive joints
}

\author{
Aurélien Doitrand ${ }^{1}$, Dominique Leguillon ${ }^{2}$ \\ ${ }^{1}$ Safran Aircraft Engines, Rond-point René Ravaud, 77550 Moissy-Cramayel, France \\ aurelien.doitrand@gmail.com \\ ${ }^{2}$ Institut Jean le Rond d'Alembert, CNRS UMR 7190, Sorbonne Universités, UPMC Université Paris 6, \\ F-75005 Paris, France \\ dominique.leguillon@upmc.fr
}

\begin{abstract}
Crack initiation of scarf adhesive joints with similar adherents is predicted through 2D and 3D applications of the coupled criterion. The joint adhesive crack initiation topology and loading are determined as a function of the joint angle and of the specimen width, using both an energy and a stress criterion consisting of the maximum interface normal or shear stress to strength ratio. Adherent/adhesive interface strength and toughness are determined by indirect confrontation to experimental results under tensile loading. The blind application of the proposed method to crack initiation of scarf adhesive joints under bending leads to a good agreement with experimental data. Compared to the 2D case, the $3 \mathrm{D}$ application of the coupled criterion allows determining the crack topology and leads to a slight better agreement with experimental results.

Keywords: A. Epoxides; B. Steels; C. Fracture mechanics ; C. Finite element stress analysis; Coupled Criterion
\end{abstract}

\section{Introduction}

Adhesively bonded joints are convenient to assemble several kind of materials and are therefore used for the load transfer between structural elements in various industrial domains including aerospace, automotive or civil engineering $[1,8]$. In particular, scarf joint [16] is an interesting kind of adhesive bonding that provides a larger adhesive bonding length than typical butt joints [7]. The design of adhesive bondings in structures requires a good knowledge of the mechanical response of the joints, including crack initiation prediction. 
Fracture of scarf adhesive joint is often predicted by performing only a stress analysis. Chen and Cheng [7] studied analytically the 2D stress distributions in a scarf joint as a function of the scarf angle and the elastic mismatch between the adhesive and the adherends. Chaudhuri and Chiu [6] developed a three-dimensional eigenfunction expansion approach for the prediction of the singular stress field at the scarf joint corner. Suzuki determined through 2D Finite Element (FE) simulations that these singular stress fields vanish for a $52^{\circ}$ scarf angle under tensile loading [32, 33]. Through 3D FE simulations, He et al. [14] and Nakano et al. $[30,31]$ found that the singular stress at the interface corner was minimum for a $60^{\circ}$ scarf angle. In several works, scarf joint failure is predicted using a stress criterion in FE simulations. Kimiaeifar et al. [15] compared Von Mises, modified Von Mises, and maximum principal stress criterions associated to a probabilistic model and showed that the choice of the stress criterion was significant for scarf failure assessment [15]. Adin [2] studied the effect of scarf angle on joint strain and failure load under tensile loading using FE calculations. The load at failure was determined when Von Mises stress reached the adhesive strength in the joint. Nakano et al. studied experimentally and numerically the influence of the scarf angle on the joint adhesive failure under tensile loading [31] and bending [30]. The failure stress was determined by comparing either Von Mises or maximum principal stress criterion inside the adhesive to the adhesive strength. However, due to the singularity at the adhesive/adherend interface corner and edges, this method seems mesh dependent (the finer the mesh, the higher the stress near the corner). Comparing Von Mises stress criterion to the adhesive strength might be adapted to predict the joint cohesive fracture since the crack initiates within the adhesive. However, in the case of adhesive fracture, the crack initiates at the adhesive/adherend interface. Therefore, this approach is no longer applicable because of the stress singularity at the interface corner, as shown by Afendi et al. [3]. In this case, the relevant fracture parameters that should be used for adhesive fracture study are those of the interface rather than those of the adhesive [3, 11, 19].

From a physical point of view, crack initiation requires two necessary conditions to be fulfilled simultaneously. The first condition states that the energy dissipated by the nucleation of a crack must be higher than the one required to initiate this crack. The second condition compares the tensile stress to the tensile strength prior to crack initiation. Both 
conditions can be expressed respectively as an energy and a stress criterion. By coupling both criterions, crack initiation can be studied in the framework of Finite Fracture Mechanics (FFM) as proposed by Leguillon [18]. The coupled criterion has already been applied to various crack initiation configurations described in the extensive review proposed by Weißgraeber et al. [35], including fracture initiation of interfaces [21, 22, 23, 25, 26, 27, 29] and joints $[4,28]$. Until now, the coupled criterion has mainly be applied in 2D. Since Leguillon extended the coupled criterion in 3D using matched asymptotic expansions [19], only few 3D applications have been performed $[10,11,13]$. Compared to the 2D case, where a crack is generally described by its length and/or its orientation, a 3D crack may be described by an infinite number of parameters $[10,35]$, which complexifies crack initiation analysis. Some assumptions can be made in order to reduce the number of parameters describing the crack shape $[10,13]$, hence preventing the real crack initiation shape determination. To overcome this difficulty, Doitrand and Leguillon recently proposed a method for 3D crack shape determination using the coupled criterion and applied it to interface crack initiation prediction in aluminum-epoxy specimens under for point bending [11]. The possible cracks were determined using the stress isocontours, so that the crack topology was described by a single parameter. Then, crack initiation shape was determined as the one fulfilling the coupled criterion that minimized the imposed loading.

In this paper, 2D and 3D applications of the coupled criterion are proposed that allows determining the crack initiation loading and topology. The studied cases, described in section 2 , are crack initiation under tensile loading and bending of scarf adhesive epoxy joints with similar steel adherent [30, 31]. A brief recall of the coupled criterion is presented in section 3. In section 4, 2D and 3D FE modeling of scarf joint are performed in order to determine crack initiation. In section 5, the adherent/adhesive interface fracture properties (strengths and toughness) are determined by confrontation of the numerical results to experimental data from [31]. Then, the proposed method is applied to the blind prediction of crack initiation in scarf joints under bending [30]. 


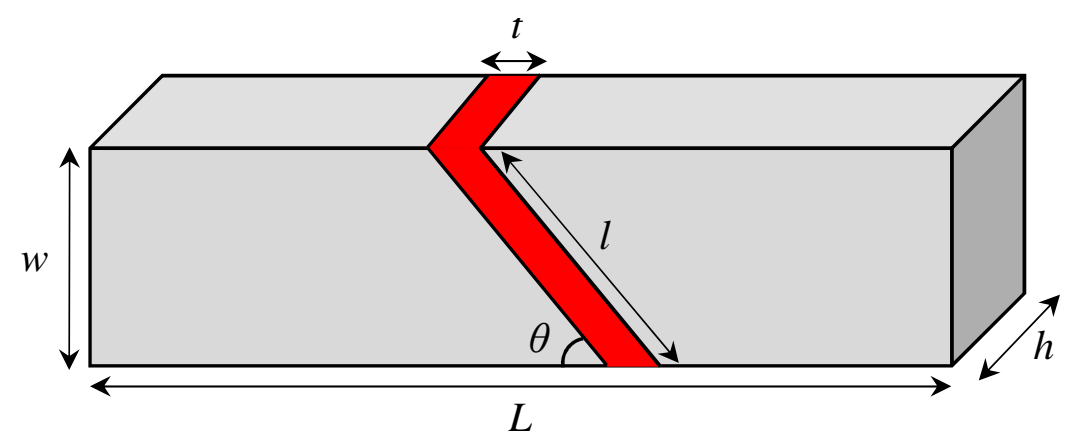

Figure 1: The scarf joint specimen consisting of two steel adherends bonded by an epoxy layer adhesive.

\section{Experimental tests and data}

The numerical problem under investigation is adhesive fracture initiation prediction in scarf joints under tensile loading and bending. The studied specimens are composed of SS400 steel adherends bonded by 3M Scotch-Weld1838 epoxy adhesive [31]. The specimen dimensions are depicted in Figure 1. Some experimental tests aiming at determining the influence of the scarf joint geometrical parameters on the stress at failure have been performed under tensile loading [31] and bending [30]. In these works, Nakano et al. determined the failure stress as a function of the scarf angle $\left(\theta=\{30,45,52,60,90\}^{\circ}\right)$ for (i) a constant specimen width $w=32 \mathrm{~mm}$ under bending and tensile loading or (ii) a constant adhesive bonding length $l=32 \mathrm{~mm}$ under tensile loading. The studied specimens are $h=9 \mathrm{~mm}$ thick, $L=200 \mathrm{~mm}$ long and the adhesive thickness $t$ is $0.1 \mathrm{~mm}$. The varying specimen dimensions in both cases are summarized in Tables 1 and 2.

\begin{tabular}{|c|c|c|c|c|c|}
\hline Scarf angle $\theta\left(^{\circ}\right)$ & 30 & 45 & 52 & 60 & 90 \\
\hline Adhesive bonding length $l(\mathrm{~mm})$ & 64 & 45.25 & 40.6 & 36.95 & 32.0 \\
\hline
\end{tabular}

Table 1: Adhesive bonding length $l$ as a function of the scarf angle $\theta$ in the case of a constant specimen width $w=32 \mathrm{~mm}$.

\begin{tabular}{|c|c|c|c|c|c|}
\hline Scarf angle $\theta\left({ }^{\circ}\right)$ & 30 & 45 & 52 & 60 & 90 \\
\hline Specimen width $w(\mathrm{~mm})$ & 16.0 & 22.6 & 25.2 & 27.7 & 32.0 \\
\hline
\end{tabular}

Table 2: Specimen width $w$ as a function of the scarf angle $\theta$ in the case of a constant adhesive bonding length $l=32 \mathrm{~mm}$. 
For all tested configurations under tensile loading or bending, a crack initiates at the adherend/adhesive interface $[30,31]$. Therefore, the relevant fracture parameters that should be involved in crack initiation analysis are the adhesive/adherend interface strength and toughness. It is difficult to identify experimentally these parameters by a direct approach. Therefore, in the following, the interface fracture parameters are determined by indirect confrontation to the experimental data in the case of tensile loading [30]. Then, a blind application to crack initiation prediction under bending [31] is performed using the obtained interface fracture parameters.

\section{The coupled criterion for crack initiation prediction}

\subsection{The coupled stress and energy criterion}

Two separate conditions must be fulfilled in order to ensure crack initiation [18]. On the one hand, stress must be high enough to damage the material and on the other hand, sufficient energy is required in order to open the crack. Both conditions can be expressed mathematically as a stress and an energy criterion. The energy condition states that the incremental energy release rate $G^{\text {inc }}$ (i.e. the ratio between the change in potential energy $W$ due to crack initiation and the crack area $S$ ) must be higher than the material critical energy release rate $G^{\mathrm{c}}$ (Equation (1)). Under the assumption of elasticity, the potential energy of both the damaged and the undamaged material, and hence the incremental energy release rate, are proportional to the square applied load $\sigma_{0}$ (Equation (1)). In Equation (1), $A$ only depends on the specimen geometry and of the material mechanical properties.

$$
G^{\mathrm{inc}}=\frac{\Delta W}{S}=\frac{W(0)-W(S)}{S}=A(S) \cdot \sigma_{0}^{2} \geq G^{\mathrm{c}}
$$

If the crack shape can be described by a set of parameters $d=\left(d_{1}, . ., d_{\mathrm{n}}\right), A(S)$ can be determined by generating response surfaces of the potential energy change, $\Delta W$, to the varying parameters $d$ by means of FE calculations with the corresponding cracked configuration [10].

The stress condition states that at crack initiation, the crack surface must be overloaded. It means that a stress criterion $f$ must be fulfilled on the whole crack surface prior to crack nucleation. Under the assumption of elasticity, the stress is proportional to the applied load 


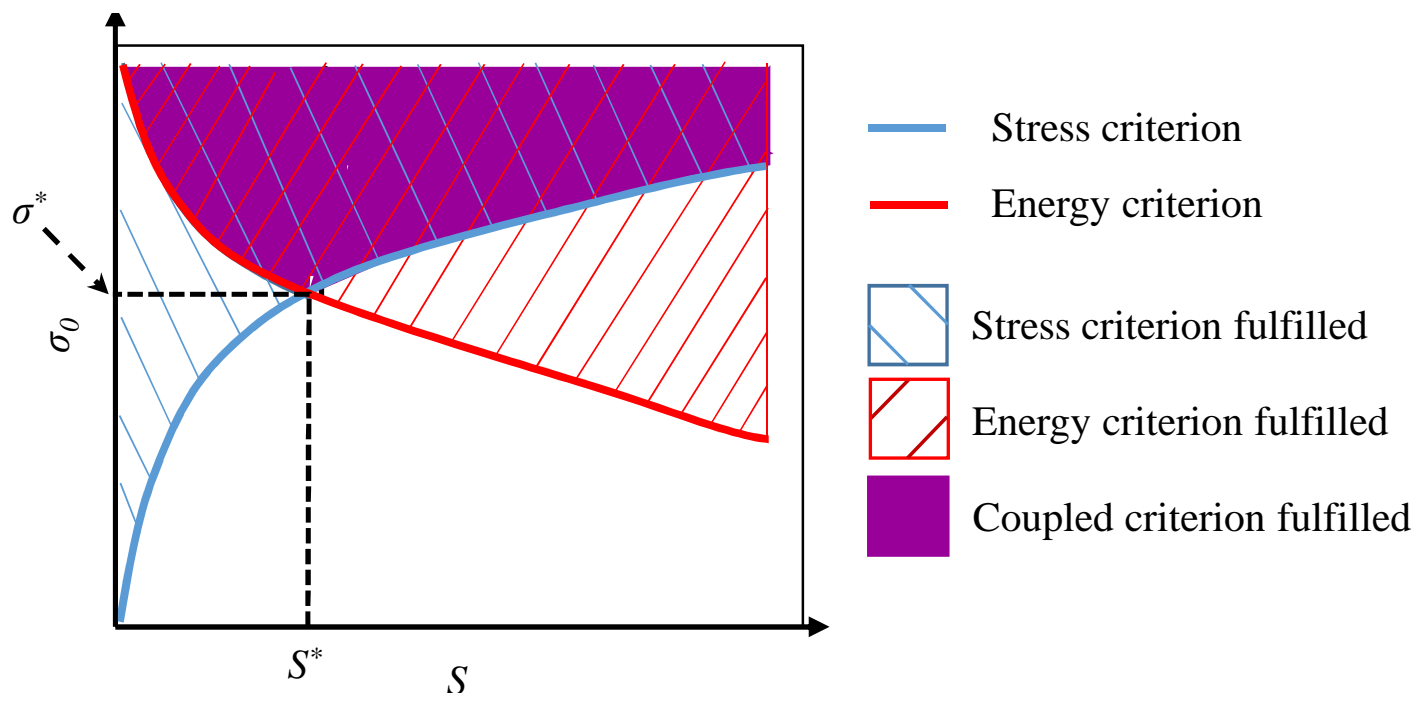

Figure 2: Imposed loading at crack initiation as a function of the crack area obtained using stress (in blue) and energy (in red) criterions. Among all admissible initation configurations (zone in purple), crack initiation configuration is determined as the one that minimizes the imposed loading (i.e., for $S=S^{*}$ ).

$\sigma_{0}$ (Equation (2)). Therefore, only one elastic calculation is needed to compute the stress condition.

$$
f(\underline{\sigma})=k(S) \cdot \sigma_{0} \geq 1
$$

The crack configuration at damage initiation (i.e. $d^{*}$ and $S^{*}$ ) can be determined as the configuration for which both the stress and the energy conditions are satisfied that minimizes the imposed loading. If $A$ and $k$ are monotonic function of $S$, such a configuration is determined by combining and solving Equations (1) and (2) (cf. Equation (3)).

$$
\frac{A(S)}{k(S)^{2}}=\frac{G^{\mathrm{c}}}{\sigma_{\mathrm{c}}^{2}}
$$

The solution of the coupled criterion in this case is shown in Figure 2, which illustrates the imposed loading necessary to fulfill the stress (in blue) and the energy (in red) criterions as a function of the crack area $S$. The purple area represents all the configurations for which the coupled criterion is fulfilled, i.e., all cracks that are likely to initiate at a certain imposed loading. Among them, the crack initiation configuration is determined as the one that minimizes the imposed loading, which corresponds to a crack of area $S^{*}$ and a loading level $\sigma^{*}$. 


\subsection{The case of non monotonic stress evolution}

Under tensile loading, it has been shown that the stresses do not exhibit a monotonic evolution along the adhesive/adherend interface of scarf joints $[5,9,31]$. The different configurations that can thus be encountered when solving the coupled criterion are shown in Figure 3.

If the solution $S^{*}$ of Equation (3) is small enough so that $\sigma^{*}<\sigma_{\min }$ (Figure 3a), or high enough so that the $\sigma^{*}>\sigma_{\max }$ (Figure $3 \mathrm{~b}$ ), the crack initiation area and load are $S^{*}$ and $\sigma^{*}$, similarly to a monotonic stress evolution ( $c f$. Figure 2). However, the case where $\sigma_{\min }<\sigma^{*}<\sigma_{\max }$ leads to alternative crack initiation configurations (Figure 3c and d), depending on the value of $S^{*}$. If $S^{*}>S_{1 \max }$ (where $S_{1 \max }$ is the crack area corresponding to the local maximum of the stress criterion, $c f$. Figure 3c), solving Equation (3) leads to an initiation stress $\sigma^{*}<\sigma_{\max }$. However, as stated previously, the stress criterion must be fulfilled on the whole surface of the crack prior to crack initiation, which implies that a crack of area $S^{*}$ may initiate only for a crack initiation loading $\sigma^{*} \geq \sigma_{\max }$. Therefore, the crack initiation area and loading are $S_{2 \max }$ and $\sigma_{\max }$ rather than $S^{*}$ and $\sigma^{*}$ (Figure 3c). This configuration has been encountered by Leguillon et al. [20] in fracture initiation prediction of layered ceramics. The last possible configuration is obtained if $\sigma_{\min }<\sigma^{*}<\sigma_{\max }$ and $S^{*}<S_{1 \max }$ (Figure 3d). It is clear that a crack of area $S^{*}\left(1^{s t}\right.$ crack in Figure 3d) is an admissible initiation crack. However, contrary to the other configurations, another crack of maximum area $S_{2}-S_{1}\left(2^{\text {nd }}\right.$ crack in Figure 3d) may also initiate since the stress criterion is also fulfilled in this zone. In this case, it is necessary to study the competition (using the energy criterion, see e.g. [24]) between the nucleation of both cracks in order to determine which crack (and possibly both) initiates.

\subsection{The choice of the stress criterion}

Kimiaeifar et al. [15] demonstrated that the choice of the stress criterion is of primary importance for scarf joint failure prediction. Interface failure is classicaly determined using a stress criterion combining the tensile and shear stress to strength ratios $[4,12,17,27]$. In the studied case, it can be shown by studying an idealized model with an infinitesimally small interface that such a criterion may not be adapted to failure stress prediction. 


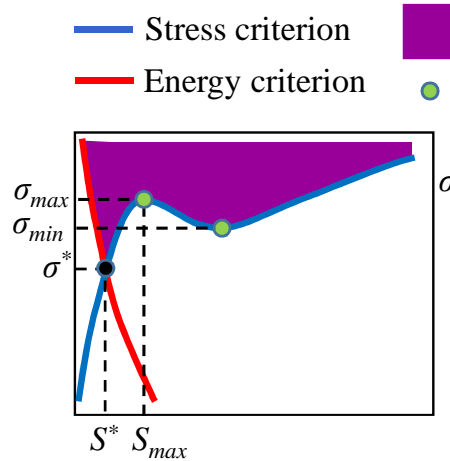

(a)

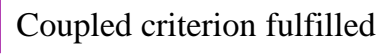

- Local Stress criterion extremum
- Crack initiation

configuration $1^{\text {st }}$ crack $2^{\text {nd }}$ crack

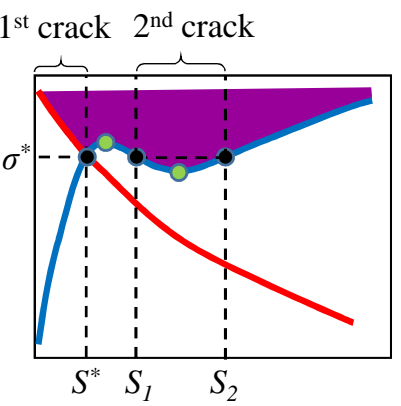

(d)

Figure 3: Possible coupled criterion solutions for a non-monotonic stress evolution. The purple zone indicates the configurations fulfilling the coupled criterion, among which the crack initiation configuration area $S^{*}$ and loading $\sigma^{*}$ can be determined (a-c). Depending on the energy criterion, a second crack is also likely to initiate (d).

The adhesive thickness $(t=0.1 \mathrm{~mm})$ is really small compared to the specimen dimensions (cf. Section 2). In a first approximation, a simple scarf joint specimen model with an infinitesimally small interface under uniform tensile loading may be studied. The interface normal $\left(\sigma_{\mathrm{nn}}\right)$ and shear $\left(\tau_{\mathrm{ns}}\right)$ stresses can be expressed as a function of the imposed stress $\sigma_{0}$ and of the scarf angle $\theta$ (Equation (4)).

$$
\left\{\begin{array}{l}
\sigma_{\mathrm{nn}}=\sigma_{0} \cdot \sin ^{2} \theta \\
\tau_{\mathrm{ns}}=\sigma_{0} \cdot \cos \theta \cdot \sin \theta
\end{array}\right.
$$

Therefore, a criterion $\left(f_{1}\right)$ combining shear and normal stress to strength ratios may be deduced from Equation (4) ( $c f$. Equation (5), where $\sigma_{\mathrm{c}}$ and $\tau_{\mathrm{c}}$ are the interface normal and shear strengths).

$$
f_{1}\left(\theta, \sigma_{0}\right)=\sqrt{\left(\frac{\sigma_{\mathrm{nn}}}{\sigma_{\mathrm{c}}}\right)^{2}+\left(\frac{\tau_{\mathrm{ns}}}{\tau_{\mathrm{c}}}\right)^{2}}=\frac{\sigma_{0}}{\sigma_{\mathrm{c}}} \cdot \sqrt{\sin ^{2} \theta \cdot\left(\sin ^{2} \theta+\left(\frac{\sigma_{\mathrm{c}}}{\tau_{\mathrm{c}}}\right)^{2} \cdot \cos ^{2} \theta\right)}
$$

For a given scarf angle $\theta$, the failure stress $\sigma_{\text {failure }}(\theta)$ such that $f_{1}\left(\theta, \sigma_{\text {failure }}(\theta)\right)=1$ can be determined as a function of the normal and shear strengths. Figure 4a shows the obtained failure stress evolution as a function of the scarf angle for several shear to normal strength ratios. It is clear that, whatever the tensile to shear strength ratio, this criterion does not allow reproducing the experimentally observed failure stress trend that increases from 

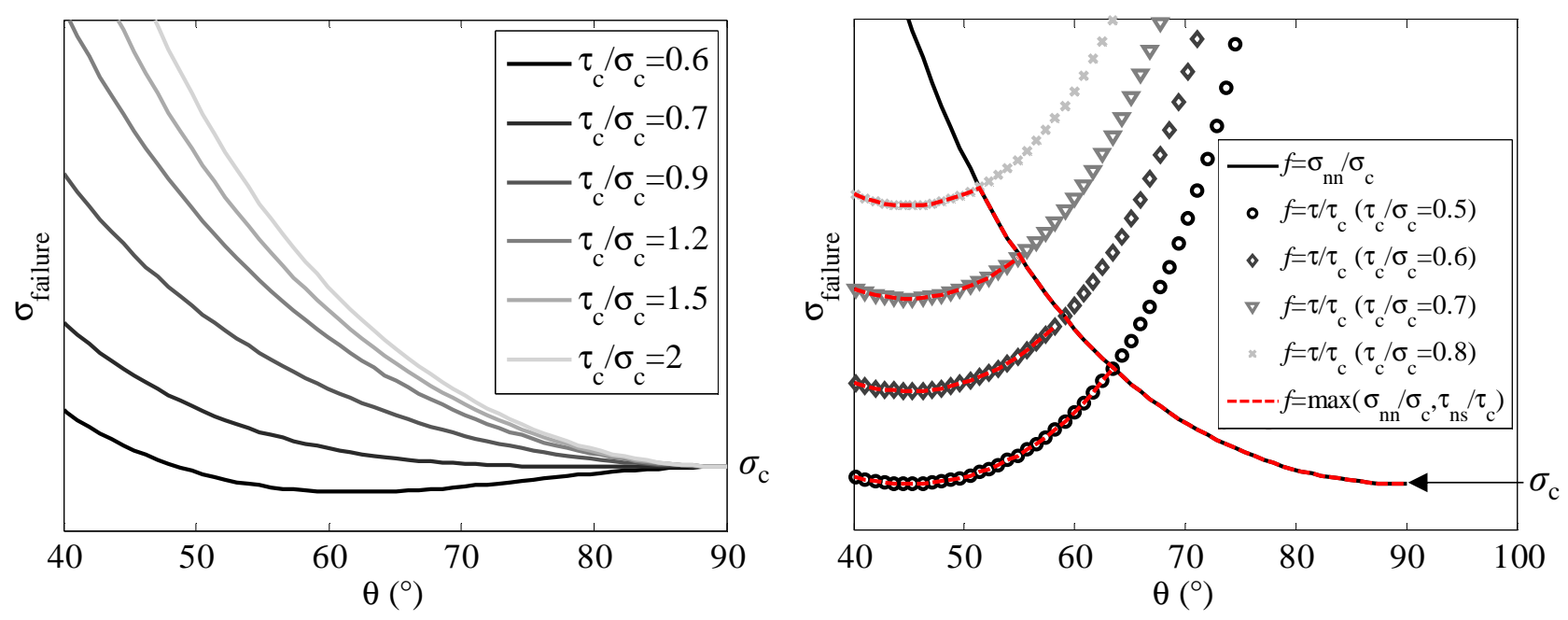

Figure 4: Failure stress as a function of scarf angle obtained using a stress criterion $f$ consisting of (a) a combination of or (b) the maximum between tensile and shear stress to strength ratios for several shear to normal strength ratios.

$45^{\circ}$ to $60^{\circ}$ scarf angles and then decreases for $90^{\circ}$ scarf angle [31]. This trend can, however, qualitatively be well reproduced by employing a stress criterion consisting of the maximum between normal or shear stress to strength ratios (Figure 4b). Coupled with the energy criterion, this stress criterion will therefore be used in the following for scarf joint crack initiation determination.

\section{Scarf joint and crack initiation modeling}

The application of the coupled criterion to the studied case requires the modeling of scarf joint specimens and boundary conditions representing bending and tensile loading. The full modeling of four point bending or tensile test as illustrated in [30] and [31] would be nonlinear, due to the contact between the spans and the specimens. Talmon l'Armée et al. [34] highlighted the possiblity to apply the coupled criterion in a nonlinear framework, however triggering much more complexity than in a linear elastic case. Therefore, the choosen boundary conditions, depicted in Figure 5a-b in the 2D case, ensures a linear elastic framework for the coupled criterion application, which means that the stress and the energy are respectively proportional to the imposed loading and the square imposed loading. For all the scarf joint configurations indicated in Tables 1 and 2, 2D meshes consisting of 4 nodes element have 


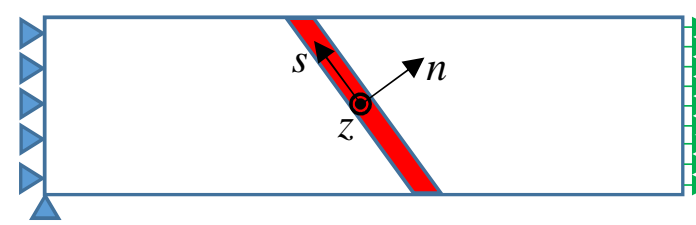

(a)

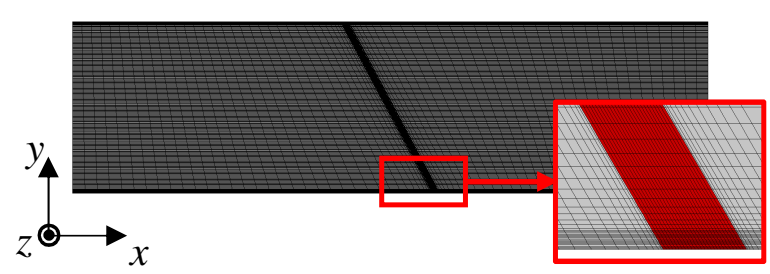

(c)

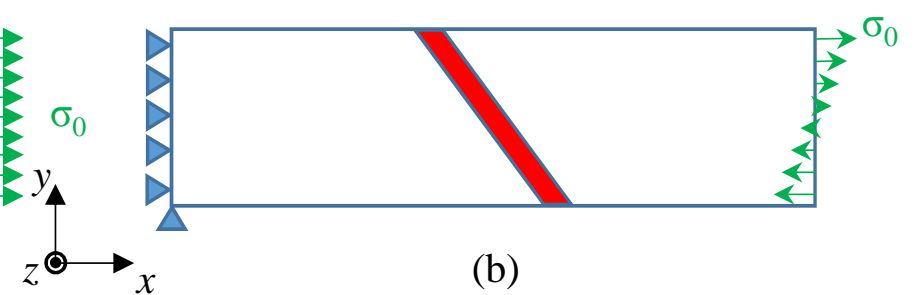

(b)

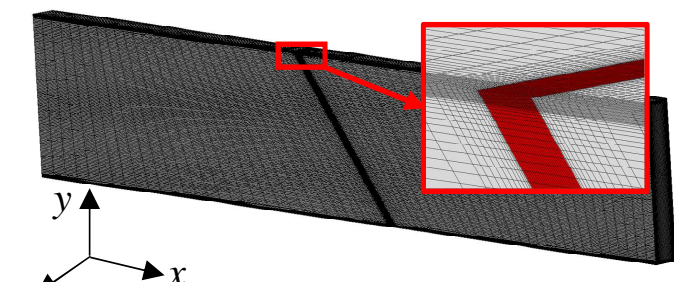

(d)

Figure 5: (a) 2D FE model boundary conditions for (a) tensile loading and (b) bending. (c) 2D and (d) 3D meshes of a specimen with a $30^{\circ}$ scarf angle and zoom on the adherend/adhesive interface corner.

been generated and extruded in order to obtain 3D meshes, the meshes being refined in the vicinity of the adhesive/adherend corner (Figure 5c-d). The material mechanical properties used in the FE calculations are taken from [31] : $E_{\text {adherend }}=209 \mathrm{GPa}, \nu_{\text {adherend }}=0.29$ for steel and $E_{\text {adhesive }}=3.34 \mathrm{GPa}, \nu_{\text {adhesive }}=0.38$ for epoxy.

The computation of the energy criterion requires the calculation of the potential energy of both the undamaged and damaged configuration, which requires the generation of the corresponding cracked meshes. 2D cracked mesh generation is straightforward since the adherend/adhesive interface crack is described by only one parameters, i.e., its length. Therefore cracked meshes are obtained by doubling the nodes along the adhesive/adherend interface to obtain a cracked mesh with a given crack length. 3D cracked mesh generation is more complex, since it requires the determination of the 3D crack shape. The same method as proposed in [11] is used herein, which consists in determining the possible crack shape based on the stress criterion isocontours. The advantages of this method is that the $3 \mathrm{D}$ crack topology is described by a single parameter, and that the stress condition of the coupled criterion (i.e. the stress criterion must be fulfilled on the whole surface of the crack prior to crack initiation) is strictly fulfilled. For each studied configuration, a first calculation has been carried out in order to determine the 2D (under plane strain assumption) and 3D stress fields at the adhesive/adherend interface and hence compute the stress condition of the 


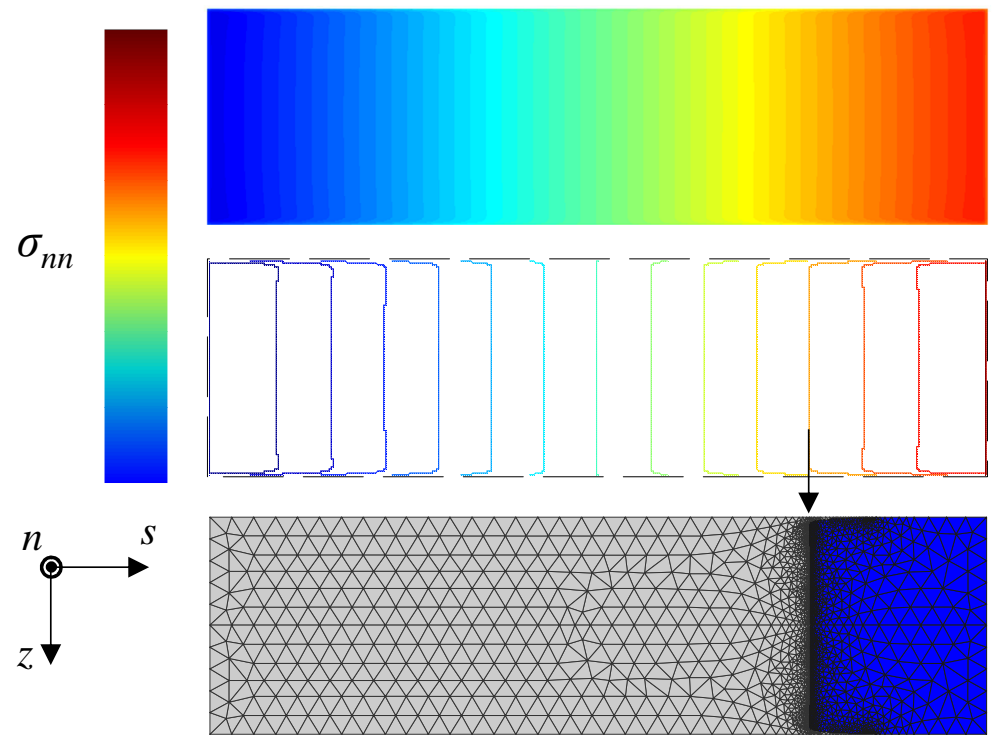

(a)

(b)

(c)

Figure 6: $15^{\circ}$ scarf joint specimen adherend/adhesive interface normal stress (a) field and (b) isovalues. (c) 2D mesh whose topology follows the crack shape determined using the stress isocontour value indicated in (b).

coupled criterion ( $c f$. Section 3.1) and the stress criterion isocontours in order to determine the possible crack initiation shapes. Figure 6a shows the interface normal stress field under bending for a $15^{\circ}$ scarf joint specimen whose dimensions are given in section 2 and Table 1. Given a value of the stress criterion isocontours (depicted in Figure 6b), an automated approach has been developped in order to generate a 2D mesh of the interface whose topology includes the crack shape based on this isocontour value (Figure 6c). The 3D scarf joint specimen mesh is then obtained by extrusion and shearing of this $2 \mathrm{D}$ mesh. The nodes located on the crack surface are finally unbuttoned in order to obtain the cracked mesh and compute the potential energy release ( $c f$. Section 3.1). It can be noted that the same mesh topology is used to compute the potential energy release, the unbutonned crack surface nodes being the only difference between the undamaged and the crack mesh, hence reducing the numerical errors. For each specimen configuration ( $c f$. Tables 2 and 1), 15 stress isocontour values have been chosen and the corresponding meshes have been generated in order to compute $W(S)$. The FE calculations have been performed using Zébulon FE solver [36]. 


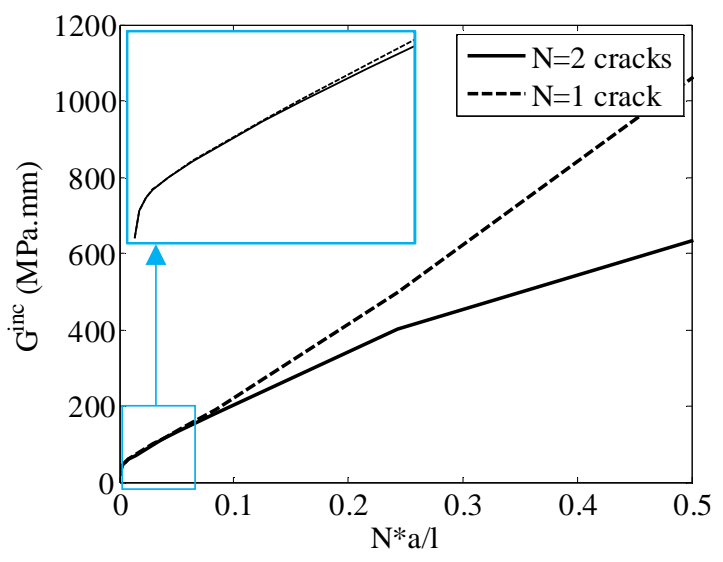

(a)

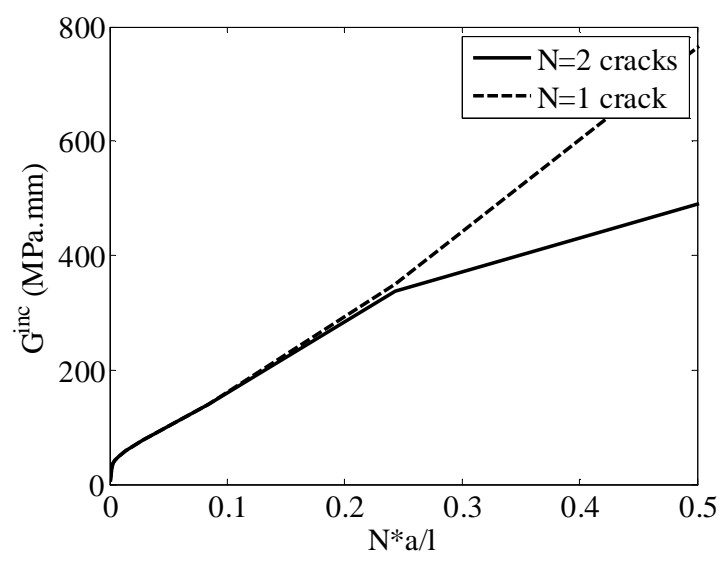

(b)

Figure 7: 2D Incremental energy release rate as a function of the normalized cracked length for (a) $15^{\circ}$ and (b) $45^{\circ}$ scarf joints.

In previous studies [5, 31], it has been shown that the stress singularity at the adherend/adhesive interface corner (and therefore crack initiation) depends on the scarf angle. In the present work, the interface corners for which the stresses are singular have been determined using calculations on undamaged configurations. In 2D (respectively in 3D), the stress field is singular at two (respectively four) adherend/adhesive corners, symmetrically located with respect to the joint center. In $2 \mathrm{D}$, whether one or two corner cracks initiate can be determined by computing the incremental energy release rate for both configurations (Figure 7), the stress criterion being fulfilled for the same loading level for both cracks due to the stress field symmetry. For small enough cracks, similar incremental energy release rates associated with one or two crack initiation are obtained, since both cracks are far enough so that they do not interact with each other. For larger crack, however, both cracks interact and one crack is more likely to initiate than two, which might be due to a shielding effect. Similar results are obtained in $3 \mathrm{D}$, leading to the conclusion than a single corner crack is more likely to initiate. The same phenomenon was also observed for 3D crack initiation in bimaterial specimen under four point bending [11]. Therefore, in the following, all the presented results concern the initiation of a single corner crack.

In section 3.2, it has been shown that for a non monotonic stress evolution, the competition between a crack starting from the corner or not (both crack lengths (in 2D) or shapes (in 3D) being determined based on stress isovalues) must be studied. This can be determined by 
computing the incremental energy release rate for the following configurations : (i) a single corner crack (depicted as the $1^{\text {st }}$ crack in Figure 3), (ii) a single non-corner crack (illustrated as the $2^{\text {nd }}$ crack in Figure 3 ) and (iii) both cracks. Similar incremental energy release rates associated to either a single non-corner crack or both cracks are obtained, which are much larger than the one associated to a single corner crack initiation. Therefore, either a single non-corner crack or both cracks are more likely to initiate than a single corner crack. This may be explain by the stress criterion local maximum ( $c f$. Figure 3) that is attained for a really small crack length (in 2D) or surface (in 3D) for which the energy release rate is small.

\section{Numerical and experimental crack initiation results}

2D and 3D applications of the coupled criterion to crack initiation prediction in scarf joints require the knowledge of the adhesive/adherend interface critical energy release rate and normal and shear strengths. These parameters are difficult to identify experimentally in a direct maneer, but can be determined by indirect confrontation to experimental results, which is done using the experimental results under tensile loading from [31]. Then, crack initiation is predicted in the case of bending and confronted to the experimental results from $[30]$.

\subsection{Crack initiation under tensile loading}

The coupled criterion presented in section 3.1 is applied to crack initiation determination in scarf joints under tensile loading. By indirect confrontation to the experimental results taken from [31], the interface fracture parameters are determined in both 2D and 3D cases. This is done by minimizing the difference between experimental crack initiation stresses and numerical predictions in a least square sense.

o $2 \mathrm{D}$ case $: G_{2 \mathrm{D}}^{\mathrm{c}}=85.010^{-3} \mathrm{MPa} \mathrm{mm}, \sigma_{\mathrm{c}}^{2 \mathrm{D}}=26.7 \mathrm{MPa}, \tau_{\mathrm{c}}^{2 \mathrm{D}}=15.2 \mathrm{MPa}$

o $3 \mathrm{D}$ case $: G_{3 \mathrm{D}}^{\mathrm{c}}=90.010^{-3} \mathrm{MPa} \mathrm{mm}, \sigma_{\mathrm{c}}^{3 \mathrm{D}}=26.7 \mathrm{MPa}, \tau_{\mathrm{c}}^{3 \mathrm{D}}=10.2 \mathrm{MPa}$

While similar values of both critical energy release rate and tensile strength are obtained, 3D simulations lead to a lower shear strength than in 2D. Figure 8 shows crack initiation stress as a function of the scarf angle obtained in 2D (Figure 8(a-b)) and 3D (Figure 8(c-d)) 


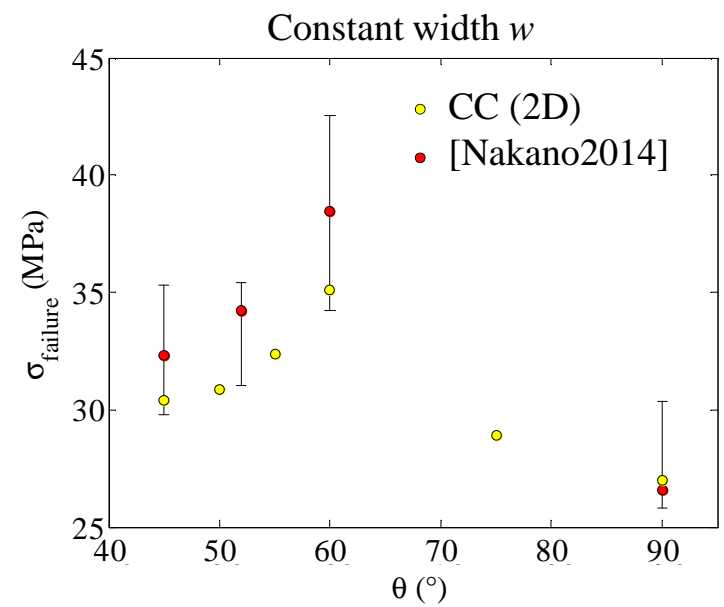

(a)

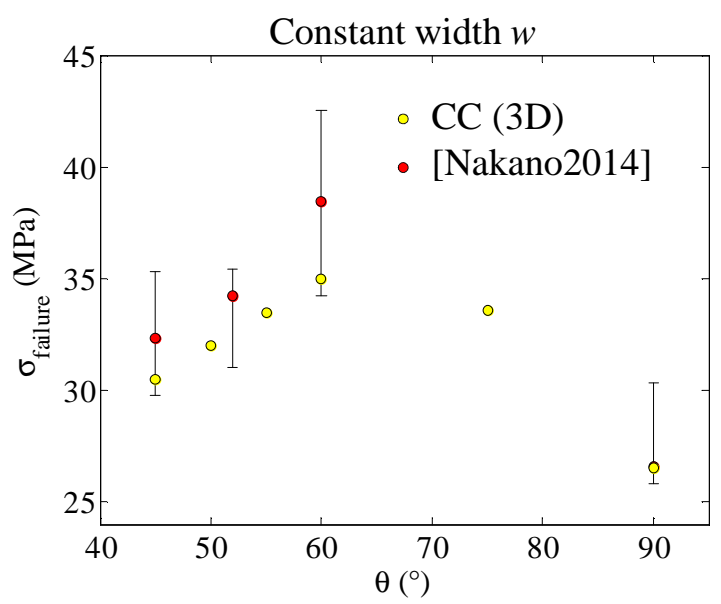

(c)

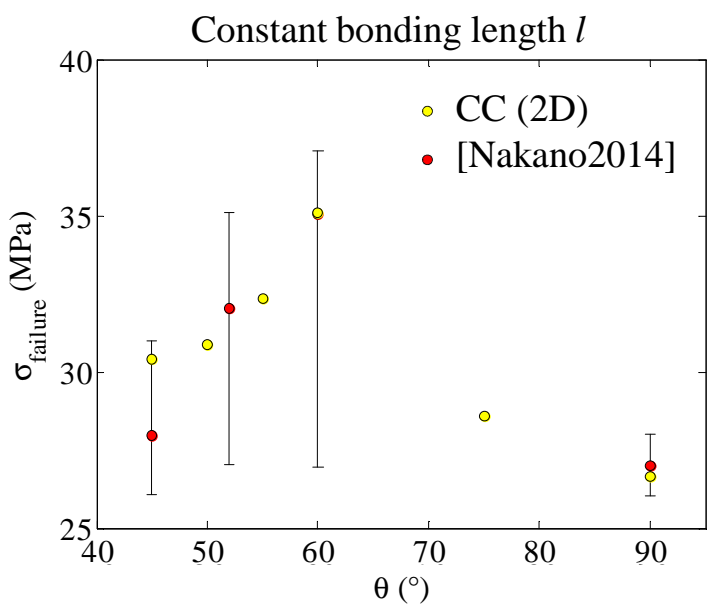

(b)

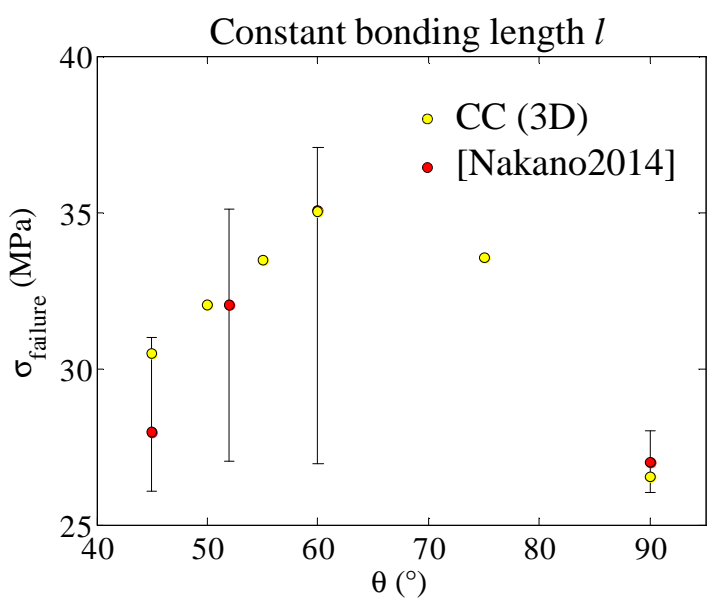

(d)

Figure 8: Crack initiation stress $\sigma_{\text {failure }}$ as a function of the scarf angle $\theta$ obtained experimentally [31] and numerically using (a-b) 2D and (c-d) 3D applications of the coupled criterion (CC) in the case of (a and c) a constant specimen width $w$ and (b and d) a constant specimen bonding length $l$.

for a constant specimen width ((Figure $8(\mathrm{a}$ and $\mathrm{c})$ ) or bonding length (Figure 8(b and d)) using the fracture parameters obtained by indirect confrontation to the experimental results. Even if the fracture parameters have been determined so as to best fit the experimental results, a satisfying agreement between numerical and experimental results is obtained since the experimental trend is well reproduced numerically. 3D simulations lead to a slighty better quantitative agreement with the experimental data compared to $2 \mathrm{D}$ results. 


\subsection{Crack initiation prediction under bending}

The coupled criterion is now applied to crack initiation prediction in scarf joint specimen under bending, using the fracture parameters determined in the previous section. Figure 9 shows crack initiation bending moment as a function of the scarf angle obtained experimentally [30] and numerically through 2D (Figure 9a) and 3D (Figure 9b) simulations. The stress evolution observed experimentally is qualitatively well reproduced using both 2D and 3D approach. Similarly to the tensile loading case, 3D simulations lead to a better quantitative agreement with experimental data then the 2D approach.

\section{Conclusion}

The proposed application of the coupled criterion allows adhesive fracture initiation prediction in scarf joints. Crack initiation topology and critical load under tensile loading and bending are determined through 2D and 3D FE simulations of undamaged and cracked scarf joint specimens. Unlike most approach involving a single stress criterion (generally Von Mises or Maximum principal stress criterion) for scarf joint crack initiation prediction, both an energy criterion and a stress criterion are employed. A criterion consisting of the combination of normal and shear stress to strength ratios, classicaly used for interface crack initiation prediction does not allow reproducing the experimentally observed crack initiation stress as

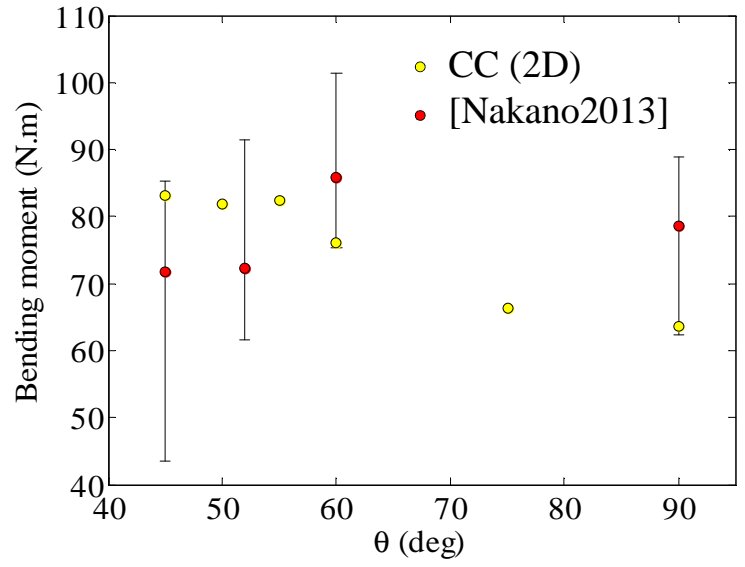

(a)

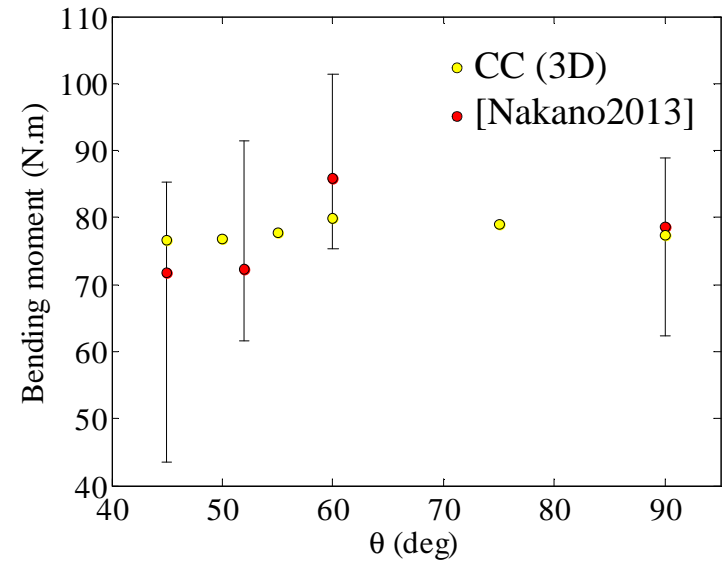

(b)

Figure 9: Bending moment at crack initiation as a function of the scarf angle $\theta$ obtained experimentally [30] and numerically using (a) 2D and 3D applications of the coupled criterion (CC). 
a function of the scarf angle. This trend is well repoduced using a stress criterion consisting of the maximum shear or tensile stress to strength ratio. 3D crack shapes are determined based on the stress criterion isocontours. Due to the non monotonic stress evolution at the adherend/adhesive interface under tensile loading, a non corner crack is more likely to initiate than a crack starting from the corner.

Adhesive/adherend toughness and tensile and shear strengths are determined by indirect confrontation to experimental results under tensile loading in the case of a constant width or adhesive bonding length. While similar values of tensile strength and toughness are obtained through $2 \mathrm{D}$ or $3 \mathrm{D}$ simulations, a lower shear strength is obtained using $3 \mathrm{D}$ simulations. The blind application of the coupled criterion to crack initiation in scarf joint specimens under bending leads to a good qualitative and quantitative agreement with experimental crack initiation stress evolution. Both under tensile loading and bending, 3D results give a slight better quantitative agreement with experimental data. 


\section{References}

[1] Adams, R.D. Adhesive bonding : science, technology and applications. Bristol: Woodhead Publishing Ltd; 2005.

[2] Adin, H., 2012. The effect of angle on the strain of scarf lap joints subjected to tensile loads. Applied Mathematical Modelling. 36, 28582867.

[3] Afendi, M., Teramoto, T., Bakri, H.B., 2011. Strength prediction of epoxy adhesively bonded scarf joints of dissimilar adherends International Journal of Adhesion and Adhesives. 31, 402411.

[4] Carrère, N., Martin, E., Leguillon, D., 2015.Comparison between models based on a coupled criterion for the prediction of the failure of adhesively bonded joints Engng. Fract. Mech. 138, 185-201.

[5] Carrère, N., Badulescu, C., Cognard, J.Y., Leguillon, D., 2015. 3D models of specimens with a scarf joint to test the adhesive and cohesive multi-axial behavior of adhesives. International Journal of Adhesion and Adhesives. 62, 154164.

[6] Chaudhuri, R.A., Chiu, S.H.J., 2009. Three-dimensional asymptotic stress field in the vicinity of an adhesively bonded scarf joint interface. Composite Structures. 89,475483.

[7] Chen, D., Sheng, S., 1990. Stress distribution in plane scarf and butt joints. Transactions of the ASME. 57, 78-83.

[8] Da Silva, L.F.M.,Ochsner, A,2008. Modeling of adhesive bonded joints. Heidelberg: Springer; 2008.

[9] Davies, P., Sohier, L., Cognard, J.Y., Bourmaud, A., Choqueuse, D., Rinnert, E, Créac'hcadec, R., 2009. Influence of adhesive bond line thickness on joint strength. International Journal of Adhesion and Adhesives. 29, 724736.

[10] Doitrand, A., Fagiano, C., Carrère, N., Chiaruttini, V., Hirsekorn, M., 2017. Damage onset modeling in woven composites based on a coupled stress and energy criterion. Engng. Fract. Mech. 169, 189-200. 
[11] Doitrand, A., Leguillon, D., XXXX. 3D application of the coupled criterion to crack initiation prediction in epoxy/aluminum specimens under four point bending. International Journal of Solids And Structures. X,X-X.

[12] García, I.G., Leguillon, D., 2012. Mixed-mode crack initiation at a v-notch in presence of an adhesive joint. International Journal of Solids and Structures. 49, 21382149.

[13] García, I.G., Carter, B.J., Ingraffea, A.R., Mantič V., 2016. A numerical study of transverse cracking in cross-ply laminates by $3 \mathrm{D}$ finite fracture mechanics. Composites Part B: Engineering 95, 475-487.

[14] He, D., Sawa, T., Karami, A., 2009.Journal of Solid Mechanics and Material Engineering.3(8):103344.

[15] Kimiaeifar, A., Toft, H., Lund, E., Thomsen, O.T., Sorensen, JD., 2012. Reliability analysis of adhesive bonded scarf joints. Engineering Structures. 35, 281287.

[16] Kumara, S.B., Sridhar, I.,Sivashanker, S., Osiyemi, S.O., Bagc, A., 2006.Tensile failure of adhesively bonded CFRP composite scarf joints. Materials Science and Engineering B.132; 113120 .

[17] Liao, L., Huang, C., Sawa, T., 2013. Effect of adhesive thickness, adhesive type and scarf angle on the mechanical properties of scarf adhesive joints. International Journal of Solids and Structures. 50, 4333-4340.

[18] Leguillon, D., 2002. Strength or toughness? A criterion for crack onset at a notch. Eur. J. Mech. - A/Solids 21 (1), 61-72.

[19] Leguillon, D., 2014. An attempt to extend the 2D coupled criterion for crack nucleation in brittle materials to the 3D case. Theor. Appl. Fract. Mech. 74, 7-17.

[20] Leguillon, D., Martin, E., Ševeček, O., Bermejo, R., 2015. Application of the coupled stress-energy criterion to predict the fracture behaviour of layered ceramics designed with internal compressive stresses. Eur. J. Mech. - A/Solids 54, 94-104. 
[21] Mantič, V., 2009. Interface crack onset at a circular cylindrical inclusion under a remote transverse tension. Application of a coupled stress and energy criterion. Int. J. Solids Structures 46, 1287-1304.

[22] Mantič, V., García, I.G., 2012. Crack onset and growth at the fibre-matrix interface under a remote biaxial transverse load. Application of a coupled stress and energy criterion. Int. J. Solids Structures 49, 2273-2290.

[23] Martin, E., Leguillon, D., 2004. Energetic conditions for interfacial failure in the vicinity of a matrix crack in brittle matrix composites. Int. J. Solids Structures 41, 6937-6948.

[24] Martin, E., Poitou, B., Leguillon, D., Gatt, J.M., 2008. Competition between deflection and penetration at an interface in the vicinity of a main crack. International Journal of Fracture. 151, 247-268.

[25] Martin, E., Leguillon, D., Carrère, N., 2010. A twofold strength and toughness criterion for the onset of free-edge shear delamination in angle-ply laminates. Int. J. Solids and Structures 47 (9), 1297-1305.

[26] Martin, E., Leguillon, D., Carrère, N., 2012. A coupled strength and toughness criterion for the prediction of the open hole tensile strength of a composite plate. Int. J. Solids and Structures 49 (26), 3915-3922.

[27] Martin, E., Vandellos, T., Leguillon, D., Carrère, N., 2016. Initiation of edge debonding: coupled criterion versus cohesive zone model. International Journal of Fracture. 199, 157168 .

[28] Moradi, A., Carrère, N., Leguillon, D., Martin, E., Cognard, J.Y., 2013. Strength prediction of bonded assemblies using a coupled criterion under elastic assumptions: Effect of material and geometrical parameters. Int. J. Adhesion and Adhesives 47, 73-82.

[29] Muñoz-Reja, M., Távara, L., Mantič, V., Cornetti, P., 2015. Crack onset and propagation at fibre-matrix elastic interfaces under biaxial loading using finite fracture mechanics. Composites: Part A. 
[30] Nakano, H., Sekiguchi, Y., Sawa, T., 2013. FEM stress analysis and strength prediction of scarf adhesive joints under static bending moments. International Journal of Adhesion and Adhesives. 44,166173.

[31] Nakano, H., Omiya, Y., Sekiguchi, Y., Sawa, T. Three-dimensional FEM stress analysis and strength prediction of scarf adhesive joints with similar adherends subjected to static tensileloadings. International Journal of Adhesion and Adhesives. 54,4050.

[32] Suzuki Y., 1985. Adhesive tensile strengths of scarf and butt joints of steel plates : 2nd report, relation between mechanical properties of adhesive and fracture criteria of joints. Bulletin of JSME. 28(245), 25752784.

[33] Suzuki Y., 1987. Adhesive Tensile Strengths of Scarf and Butt Joints of Steel Plates (Relation Between Adhesive Layer Thicknesses and Adhesive Strengths of Joints) : SolidMechanics, Strength of Materials. JSME International Journal. 30(265), 10421051.

[34] Talmon l'Armée, A., Hell, S., Rosendahl, P.L., Felger, J., 2017. Nonlinear crack opening integral : Mode mixity for finite cracks. Engineering Fracture Mechanics. 186, 283-299.

[35] Weißgraeber, P., Leguillon, D., Becker, W., 2016. A review of Finite Fracture Mechanics: crack initiation at singular and non-singular stress raisers. Archive Appl. Mech. 86 (1-2), 375401.

[36] http://www.zset-software.com/products/zebulon/ 